\title{
MYTHODRAMA GROUP PSYCHOTHERAPY APPROACH FOR ADOLESCENTS WITH BEHAVIOR DIFFICULTIES
}

\author{
Tinatin Tiabashvili, Rusudan Mirtskhulava, Marine Japaridze \\ Ilia State University, Georgia \\ E-mail: Tinatin.tiabashvili@iliauni.edu.ge, Rusudan.mirtskhuava@iliauni.edu.ge, \\ Marine_japaridze@iliauni.edu.ge
}

\begin{abstract}
Mythodrama group psychotherapy approach of resolving conflict and bullying has been successful as an intervention in a school setting. This study aimed to provide further evaluation of Mythodrama group approach. A total of 97 Georgian adolescents (Mean of age $=14.65$, SD $=1.76$ ) participated in the controlled experimental study. Participants of the experimental group received a Mythodrama group intervention during a period of three months. Analyses revealed a significant increase in emotional intelligence, prosocial behavior and adaptive coping strategies in the intervention group. No significant changes were observed in the control group. The findings suggest that adolescents'behavior, trait emotional intelligence and coping strategies can be improved using Mythodrama intervention. Follow-up research is required to reveal the persistence and replicability of the result.
\end{abstract}

Keywords: mythodrama for adolescents, behavior problems, trait EI, coping strategies.

\section{Introduction}

Increasingly large numbers of adolescents are exhibiting difficulties at school, linked to behavioral problems. Researchers have classified these problems into two broad categories: externalizing and internalizing behavior problems Externalizing behaviors represent conduct problems specifically aggressiveness, antisocial behavior, violence and delinquency while internalizing behaviors deal with emotional concerns such as anxiety, depression and withdrawn behavior (Achenbach, 1991). The development of behavior problems is connected with individual risk factors as well as family influences, poverty, relationship with peers and social disadvantage. Group psychotherapy has been effective in addressing behavior difficulties of adolescents regardless of whether they are developmental or induced by stressful life events (Hoag, Burlingame, 1997).

This study uses the Mythodrama group psychotherapy approach developed by Dr. Allan Guggenbühl. The approach is based on the idea of analytical psychology considering that behavior difficulties could be seen as a symptom that carries important messages that should be taken into consideration when interpreting the behavior. Mythodrama is a creative method that uses myths and stories as the main tool of the intervention (Guggenbühl, 1999). Stories enable adolescents to develop images that represent the unconscious motives and repressed complexes. This process 
96 of symbolizing what might lie behind the emotional problems or aggression makes it possible for adolescents to speak about their difficulties in a playful way and find a new perspective (Guggenbühl, 2008). It is worth noting that stories do not necessarily have to carry any educative or moral messages. The stories are used to stimulate the students mentally. For this purpose, stories are not narrated to the end. They are stopped just before a dramatic turning point or culmination. This enables the students to fantasize about their own version of ending and share and discuss it with the group members.

Originally Mythodrama was created as a method for group therapy for children and adolescents with behavioral and emotional problems. Later the method was included into seven step crisis intervention program adapted to a school setting. The seven-step program has been successful in Switzerland, Sweden (Guggenbühl at al., 2006) and The United States (Al-Sammaray, 2011) due to the group technique used which has helped students deal with violence, conflict, aggression, and bullying. The technique was implemented as "Mythodrama" in Tbilisi (Georgia) schools under the supervision of Dr. Guggenbühl in 2009. The aim of the current study was to provide an exploration of the efficacy of Mythodrama group approach for adolescents in relation with emotional intelligence, coping strategies and behavior problems. In the last few decades, research has seen the link between emotional Intelligence and adaptive coping styles for mental health (Lazarus \& Folkman, 1984; Mayer \& Salovey, 1997). However, research studying the relationship between coping and emotional intelligence vary significantly depending on the model EI defined and measured - Trait EI versus Ability EI. Trait EI or trait emotional self-efficacy is defined as a "constellation of emotion-related self-perceptions and dispositions located at the lower levels of personality hierarchies" (Petrides et al, 2007, p.26) and is measured by self-report questionnaires. Ability EI considers emotional-related abilities and should be measured by means of performance tests similarly as psychometric intelligence is measured (Petrides \& Furnham, 2000, 2003; Smith, Heaven, \& Ciarrochi, 2008). Recent research shows that trait EI scores are related to adaptive coping strategies and prosocial behaviors in adolescents (Mavroveli at al., 2007; Petrides at al., 2006; Petrides, Frederickson, \& Furnham, 2004). Furthermore, data from adult sample shows that trait emotional self-efficacy is associated with leadership, happiness, psychological well-being, social relationships, emotion management and emotion identification (Villanueva \& Sanchez, 2007; Chamorro-Premuzic, Bennet, \& Furnham, 2007; Nelis at al., 2011; Mikolajczak, Nelis, Hansenne, \& Quoidbach, 2008).

Based on the above assumptions, the study intended to address the following questions: Is Mythodrama an effective intervention in reducing behavioral problems among middle and late adolescents? Is Mythodrama group intervention effective in optimizing trait EI and adaptive coping styles among middle and late adolescents? The hypothesis included: 1. trait EI could be improved among adolescents after receiving Mythodrama group psychotherapy intervention; 2 . coping styles could be changed from maladaptive to adaptive styles after receiving Mythodrama intervention; 3. adolescent behavior problems could be decreased after receiving Mythodrama intervention.

\section{Research Methodology}

\section{Design}

The quantitative study was designed to examine the effect of Mythodrama intervention in relation to behavior problems, trait emotional intelligence and coping strategies on a sample of public school learners.

A mixed model group (intervention vs. control) repeated measures analysis of variances (ANOVAs) was performed to indicate differences that occurred within the two groups. 
The sample consisted of 97 participants, 40 in the Mythodrama groups, 57 in the wait-list control group. The Mythodrama group comprised of $48.67 \%$ female and $51.33 \%$ male, whilst the control group consisted of $52.6 \%$ female and $47.4 \%$ male. All of the participants were public school students (Tbilisi, Georgia) aged between 13 and 18 (Mean of age $=14.66 S D=1.76)$. The participants for both groups were selected based on emotional and behavioral problems reported by their school teachers.

\section{Procedure}

Teachers in the four Tbilisi public schools identified students who demonstrated emotional and behavioral difficulties within the school during the last six months. The teacher's report of the pupils included aggressive behavior, bullying, difficulties interacting with peers, social exclusion, a negative self-concept, low self-esteem, anxiety, depression, verbal insults towards other students, a difficult family background which included domestic abuse, and physical violence with others and difficulties in following classroom rules. There were 40 students randomly included in Mythodrama groups led by specially trained psychologists - 9 to 11 students and three psychologists per group. Before starting the intervention, we received consent from the students and their parents to participate in Mythodrama groups. In accordance with the methodological frame of Mythodrama intervention, teachers and parents did not attend the sessions. The 57 wait-list control group participants did not receive Mythodrama intervention during the study.

Each group met in total 12-15 times, a two-hour session once a week within their school building. The sessions followed one and the same format: 1 . welcome; 2 . energizer game; 3 . story; 4. make up the ending of the story individually; 6 . sharing it with the group; 5 . performance; 6 . discussion; 7. finishing game (for thorough description of the set see Guggenbühl at al., 2006).

\section{Measures}

The effectiveness of the intervention was assessed through the following measures:

The Georgian version of Trait Emotional Intelligence Questionnaire Adolescent form (TEIQueAF) (Petrides, 2009). This version is modeled on the full form of the TEIQue and is intended to yield scores on the same fifteen facets, four factors (Well-being, Self-control, Emotionality, and Sociability) and global trait EI. The TEIQue comprises 153 items (e.g. 'I often find it hard to understand other people'), responded to on a 7-point scale from 1 (completely disagree) to 7 (completely agree).

The Georgian version of Coping Inventory for Stressful Situations (CISS) - Adolescent Form (Endler, N. S., \& Parker, J. D. A. 1990). The CISS is a self-report measure of Emotion-, Task-, and Avoidance-oriented coping. The CISS comprises 20 items arranged on a 4-point scale from 1 (strongly disagree) to 4 (strongly agree).

The participants of Mythodrama groups completed these two measures twice: once prior to the Mythodrama intervention and the second at the completion of the intervention. Participants of the control groups completed the same measures as the training group but did not attend the Mythodrama sessions.

The Georgian version of Strengths and Difficulties Questionnaire - (SDQ) (Goodman, 1997). The SDQ consists of 25 items that produce scores in five areas: emotional difficulties, conduct problems, hyperactivity, peer relationships and prosocial behavior. The teacher ratings were obtained for only Mythodrama participants.

\section{Research Results}

The baseline differences between the intervention and control group are shown in Table 1 . Significant differences were noticed concerning only two factors of TEIQue - well-being and global EI, for which the scores in the control group were higher. 
Table 1. Means, standard deviations, and significance of differences between training and control group prior to mythodrama intervention.

\begin{tabular}{lcccccc}
\hline & \multicolumn{3}{c}{ Intervention group $(\boldsymbol{n}=\mathbf{4 0})$} & \multicolumn{3}{c}{ Control group $(\boldsymbol{n}=\mathbf{5 7})$} \\
\hline \multicolumn{1}{c}{ Variable } & $\boldsymbol{M}$ & $\boldsymbol{S D}$ & $\boldsymbol{M}$ & $\boldsymbol{S D}$ & $\boldsymbol{t}(\mathbf{9 5})$ & $\boldsymbol{p}$ \\
\hline Emotionality & 4.49 & .81 & 4.75 & .79 & 1.57 & .119 \\
Sociability & 4.53 & .85 & 4.71 & .73 & 1.10 & .273 \\
Well-being & 4.78 & 1.13 & 5.27 & .97 & 2.30 & .023 \\
Self-control & 4.04 & .92 & 4.26 & .80 & 1.27 & .206 \\
Global trait El & 4.43 & .78 & 4.73 & .63 & 2.10 & .038 \\
Task-oriented coping & 2.83 & .58 & 2.82 & .41 & -1.11 & .913 \\
Emotion-oriented coping & 2.70 & .48 & 2.48 & .67 & 1.72 & .087 \\
Avoidance-oriented coping & 2.39 & .64 & 2.55 & .60 & 1.30 & .196 \\
\hline
\end{tabular}

Note. El = emotional intelligence.

The Mixed-Model Group (intervention vs. control) and Time (Time 1 vs. Time 2) repeated measure analyses of variance (ANOVA) were performed on each measure, with the group as the subject factor and time as the within-subject factor. No significant change was reported in the control group except the emotionality, however, there was a significant change in the Mythodrama group, indicating an increase in global trait EI, emotionality, sociability, well-being, self- control and adaptive coping strategies.

Analyses revealed a significant Group and Time interaction for global trait EI, $F(1,95)=$ 23.0, $p<.001, \eta \mathrm{p}^{2}=.19$; and for four Trait EI factors, namely: emotionality, $F(1,95)=34.7, p<$ .001 , estimate $\eta p^{2}=.27$; sociability, $F(1,95)=11.6, p<.001, \eta p^{2}=.11$; well-being, $F(1,95)=11.6$, $p=.016, \eta \mathrm{p}^{2}=.06$; self-control, $F(1,95)=37.7, p<.001, \eta \mathrm{p}^{2}=.28$; Significant Group and Time interactions were found for task-oriented coping, $F(1,95)=38.4, p<.001, \eta \mathrm{p}^{2}=.28$; avoidanceoriented coping, $F(1,95)=4.33, p=.04, \eta \mathrm{p}^{2}=.04$. No significant Group and Time interaction was found for emotion-oriented coping, $F(1,95)=.45, p=.50, \eta \mathrm{p}^{2}=.00$. The means, standard deviations, and $p$ value between Time 1 and Time 2 for each variable and group are shown in Table 2 .

Table 2. Means, standard deviations, and significance of differences between time 1 and time 2 for each variable and each group.

\begin{tabular}{lcccccccc}
\hline & \multicolumn{3}{c}{ Intervention group $(\mathrm{n}=40)$} & \multicolumn{5}{c}{ Control group $(\mathrm{n}=57)$} \\
\cline { 2 - 10 } & Time 1 & Time 2 & & & Time 1 & Time 2 \\
\hline Variable & $M(S D)$ & $M(S D)$ & $F(1.39)$ & $p$ & $M(S D)$ & $M(S D)$ & $F(1.56)$ & $p$ \\
Emotionality & $4.49(.81)$ & $5.46(.52)$ & 80.13 & .00 & $4.75(.79)$ & $4.93(.98)$ & 4.67 & .04 \\
Sociability & $4.53(.85)$ & $5.09(.57)$ & 26.95 & .00 & $4.71(.73)$ & $4.79(.90)$ & .83 & .365 \\
Well-being & $4.78(1.13)$ & $5.35(.91)$ & 8.12 & .00 & $5.27(.97)$ & $5.37(1.17)$ & 1.18 & .280 \\
Self-control & $4.04(.92)$ & $4.81(.90)$ & 52.85 & .00 & $4.26(.80)$ & $4.20(1.01)$ & .43 & .521 \\
Global trait El & $4.43(.78)$ & $5.14(.66)$ & 38.54 & .00 & $4.73(.63)$ & $4.81(.90)$ & 1.09 & .352 \\
Task-oriented coping & $2.83(.58)$ & $3.46(.49)$ & 32.95 & .00 & $2.82(.41)$ & $2.84(.35)$ & .36 & .546 \\
Emotion-oriented coping & $2.70(.48)$ & $2.61(.53)$ & 1.69 & .20 & $2.48(.67)$ & $2.45(.69)$ & .40 & .525 \\
Avoidance-oriented coping & $2.39(.64)$ & $2.25(.54)$ & 23.96 & .04 & $2.55(.60)$ & $2.52(.57)$ & .57 & .453 \\
\hline
\end{tabular}

In order to reveal the association between global trait EI and coping strategies, correlation analysis was done. The results indicate that there was a significant positive correlation between Global EI and task-oriented coping, $r(95)=.491, p<.001$, and negative correlation between 
emotion-oriented coping $r(95)=-.261, p=.01$, and avoidance-oriented coping $r(95)=-.345, p$ $<.0001$ (Table 3).

Table 3. Pearson correlation coefficient and descriptive statistics of Global Trait EI (TEIQue-AF) and coping strategies.

\begin{tabular}{lcccccc}
\hline & $\mathbf{1}$ & $\mathbf{2}$ & $\mathbf{3}$ & $\mathbf{4}$ & $\mathbf{M}$ & $\mathbf{S D}$ \\
\hline 1. Global Trait El & 1.00 & & & & 4.95 & .83 \\
2. Problem-oriented coping & .49 & 1.00 & & & 3.10 & .52 \\
3. Emotion-oriented coping & -.26 & -.05 & 1.00 & & 2.52 & .64 \\
4. Avoidance-oriented coping & -.35 & -.30 & .40 & 1.00 & 2.41 & .58 \\
\hline
\end{tabular}

A one-way repeated measure analyses of variances (ANOVA) of teachers SDQ revealed significant changes in the Mythodrama group across time for emotional symptoms, $F(1,39)=4.88$, $p=.033, \eta \mathrm{p}^{2}=.111$, conductial problems, $F(1,39)=45.92, p<.001, \eta \mathrm{p}^{2}=.541$, prosocial behavior, $F(1,39)=71.48, p<.001, \eta \mathrm{p}^{2}=.647$, and peer problems, $F(1,39)=30.37, p<.001, \eta \mathrm{p}^{2}=.438$; no significant changes were found for hyperactivity, $F(1,39)=3.85, p=.057, \eta p^{2}=.090$. See Table 4 for more details.

Table 4. Means, standard deviations, and significance of differences between time 1 and time 2 of teachers SDQ ratings for Mythodrama group.

\begin{tabular}{lccccc}
\hline & Time 1 & & \multicolumn{3}{c}{ Time 2 } \\
\cline { 2 - 3 } \cline { 5 - 6 } \multicolumn{1}{c}{ Variable } & $\mathbf{M}(\mathbf{S D})$ & & $\mathbf{M}(\mathbf{S D})$ & $\mathbf{F}(1.39)$ & $\mathbf{p}$ \\
\hline Emotion difficulties & $4.25(2.23)$ & & $4.07(2.21)$ & 4.88 & .033 \\
conduct problems & $3.37(1.93)$ & & $2.15(1.35)$ & 45.92 & $<.001$ \\
Hyperactivity & $6.50(1.83)$ & & $6.35(1.90)$ & 3.85 & .057 \\
Peer problems & $5.15(1.29)$ & & $4.25(1.39)$ & 30.37 & $<.001$ \\
Prosocial behavior & $4.60(2.14)$ & & $6.05(2.08)$ & 71.48 & $<.001$ \\
\hline
\end{tabular}

The teacher ratings of behavior difficulties of adolescents were obtained for only the intervention groups.

\section{Discussion}

The rationale of this study was to investigate the effects of using the Mythodrama group psychotherapy approach for middle and late adolescents. The results indicate that the Mythodrama group psychotherapy approach is an effective form of intervention for adolescents with emotional and behavior problems. The significant change was not reported in the controlled group, however there was significant improvement of emotional competencies and global trait emotional intelligence as well as adaptive coping strategies in the intervention group. Teachers' ratings for Mythodrama group participants showed a significant improvement in prosocial behavior, conduct problems, emotional difficulties and peer problems. These findings are consistent with Guggenbühl at al., (2006) who reported significant improvements of adolescent behavior relating aggression and bullying.

It can be concluded that the Mythodrama approach is effective for increasing trait emotional intelligence and adaptive coping styles among middle and late adolescents. More specifically, the findings conclude that compared with the control group, the intervention group showed a significant improvement in well-being, sociability, emotionality, self-control and overall emotional self-efficacy directly after the intervention. The findings support previous studies of the Mytho- 
drama effect (Tiabashvili, Mirtskhulava \& Japaridze, 2015) which suggests that Mythodrama is an effective intervention for optimizing emotional self-efficacy among early adolescents. The results of the presented study are similar to those of several studies addressing the question of optimizing trait emotional intelligence by means of carefully developed training programs, psychological interventions or creative programs (see also Ali, 2017; Nelis et al., 2009; Ruttledge \& Petrides, 2011,).

Although, the findings revealed that after Mythodrama intervention task-oriented coping was increased while avoidance-oriented coping was decreased. The emotion-oriented coping did not reach any significant difference over time right after the intervention. As previous research indicates problem-solving or task-oriented coping styles contribute well-being and better adjustment within the environment (Turashvili \& Japaridze, 2013), while emotion-focused coping is likely to be associated with behavioral problems, poor adjustment, as well as physical and emotional stress (Causey \& Dubow, 1992; Eschenbeck et al., 2012). Research shows that emotion-oriented coping can be effective when aimed at reducing the emotional distress which can lead to more task-oriented coping strategies later, but when it is obstinate it prevents from task-oriented coping and will result in maladjustment (Endler \& Parker, 1990; Lobel, Gilat \& Endler, 1993). There was no significant change of emotion-oriented coping after the intervention in the current study; however, participants should be investigated over the next few months to determine if this coping strategy applies for a long term.

In terms of the relationship between the trait EI and coping strategies, the current research shows that trait EI was positively correlated with adaptive coping, namely task-oriented coping and negatively associated with maladaptive copings, such as emotional and avoidance-oriented coping. These findings suggest that adolescents with high trait EI are likely to cope with everyday problems effectively compared to their low trait EI peers, which relates to other research as well (see Mavroveli et al., 2007, Mikolajczak et al., 2006; Petrides, Pe'rez-Gonza'lez et al., 2007). Research points out that well-being component of trait EI appears to be relevant in the adjustment process, noting that positive emotions promote the development of those physical, intellectual and social resources that are necessary for successful coping (Frederickson, 1998).

The present research has essential theoretical and practical implications. At the theoretical level, the interpretation of the results gives the possibility to consider Mythodrama group work as an effective type of intervention for decreasing behavior problems, optimizing trait emotional intelligence and adaptive coping strategies among middle and late adolescents. This is the first attempt to investigate how Mythodrama intervention leads to an improvement of emotional functioning, coping strategies and behavior of adolescents. At the practical level, the results of the study are notable as it seems clear that a person's self-efficacy is connected with numerous positive psychological outcomes. Research indicates that trait EI self-perceptions and dispositions have a substantial impact on peer relations, social skills, as well as psychopathology and overall psychological wellbeing (Petrides et al., 2006; Petrides et al., 2004). Furthermore, researchers have identified that peer popularity and social networks are part of the mechanisms that prevent high trait EI individuals to show psychopathology, antisocial behavior and delinquency (Austin, Saklofske, \& Egan, 2005).

\section{Conclusions}

The present research finding shows that Mythodrama group psychotherapy approach is an effective intervention for middle and late adolescents. The results indicate significant improvement of adolescents' trait EI, adaptive coping strategies and prosocial behavior after receiving Mythodrama intervention. The findings recommend a new aspect of Mythodrama which is a relatively new method and the implication of such intervention for adolescent's emotional intelligence was mostly unknown. However, despite its contribution, several limitations were evident throughout the authors methodologies used in the research: in order to get substantial conclusions about the longterm effects of the intervention, the current results would have to be matched up with six-month follow-up results; the data from teachers was gathered only from Mythodrama group participants. Quantitative measures would have to be done for a control group in order to come to substantial conclusions about the effects of intervention. 


\section{References}

Achenbach, T. M. (1991). Manual for the teacher's report form and 1991 profile. Burlington, VT: University of Vermont Department of Psychiatry

Ali, S. (2017). Inside out and counseling: Creative interventions to facilitate emotional intelligence. Journal of Creativity in Mental Health, 1-11. doi: 10.1080/15401383.2016.1275995.

Al-Sammarai, L. (2011). Evaluation of Mythodrama intervention among middle school children (Doctoral dissertation). Retrieved from ProQuest Dissertations and Theses. (Accession Order No. UMI 3556973).

Austin, E. J., Saklofske, D. H., \& Egan, V. (2005). Personality, well-being, and health correlates of trait emotional intelligence. Personality and Individual Differences, 38, 547-558. doi: 10.1016/j.paid.2004.05.009.

Causey, D. L., \& Dubow, E. F. (1992). Development of a self-report coping measure for elementary school children. Journal of Clinical Child Psychology, 21(1), 47-59. doi:10.1207/s15374424jccp2101_8

Chamorro-Premuzic, T., Bennett, E., \& Furnham, A. (2007). The happy personality: Mediational role of trait emotional intelligence. Personality and Individual Differences, 42, 1633-1639. doi:10.1016/j. paid.2006.10.029.

Endler, N. S., \& Parker, J. D. A. (1990). Multidimensional assessment of coping: A critical evaluation. Journal of Personality and Social Psychology, 58 (5), 844-854. doi:10.1037/0022-3514.58.5.844.

Eschenbeck, H., Heim-Dreger, U. Tasdaban, E. Lohaus, A., \& Kohlmann, C-W. (2012). A Turkish adaptation of the Coping Scales from the German Stress and Coping Questionnaire for children and adolescents. European Journal of Psychological Assessment, 28 (1), 32-40. doi: 10.1027/1015-5759/a000088.

Frederickson, B. L. (1998). What good are positive emotions? Review of General Psychology, 2, 300-319. doi:10.1037/1089-2680.2.3.300.

Goodman, R. (1997). The strengths and difficulties questionnaire: A research note. Journal of Child Psychology and Psychiatry, 38, 581-586. doi: 10.1111/j.1469-7610.1997.tb01545.x.

Guggenbühl, A. (1999). Das Mythodrama [The Mythodrama]. Zürich, IKM.

Guggenbühl A., Hersberger K., Rom T., \& Bostrom, P. (2006). Helping schools in crisis-a scientific evaluation of the mythodrama intervention approach in Swiss and Swedish schools. Zurich, IKM.

Guggenbühl, A., (2008). Education and Imagination: A contradiction in terms? Experiences from mythodramatic crisis intervention in schools. In R. A. Jones, A. Clarkson, S. Congram \& N. Stratton (Eds.), Education and imagination: Post-Jungian Perspectives. (pp. 64 - 78). London and New York: Taylor \& Francis.

Hoag, M. J., Burlingame, G. M. (1997). Evaluating the effectiveness of child and adolescent group treatment: A meta-analytic review. Journal of Clinical \& Child Psychology, 26 (3), 234-46. doi: 10.1207/ s15374424jccp2603_2

Lazarus, R. S., \& Folkman, S. (1984). Stress, appraisal, and coping. New York: Springer.

Lobel, T. E., Gilat, I., \& Endler, N. S. (1993). The Gulf War: Distressful reactions to scud missiles attack. Anxiety, Stress and Coping, 6, 9-23. doi: 10.1111/j.1540-4560.1993.tb01183.x.

Mavroveli, S, Petrides, K. V., Rieffe, C., \& Bakker F. (2007). Trait emotional intelligence, psychological wellbeing and peer-rated social competence in adolescence. British Journal of Developmental Psychology, 25, 263-27. doi:10.1348/026151006X118577.

Mayer, J. D., \& Salovey, P. (1997). What is emotional intelligence? In P. Salovey \& D. J. Sluyter (Eds.), Emotional development and emotional intelligence: Educational implications (pp. 3-34). New York: Harper Collins.

Mikolajczak, M., Luminet, O., \& Menil, C. (2006). Predicting resistance to stress: Incremental validity of trait emotional intelligence over alexithymia and optimism. Psicothema, 18 (Suppl), 79-88.

Mikolajczak, M., Nelis, D., Hansenne, M., \& Quoidbach, J. (2008). If you can regulate sadness, you can probably regulate shame: Associations between trait emotional intelligence, emotion regulation and coping efficiency across discrete emotions. Personality and Individual Differences, 44, 1356-1368. doi: 10.1016/j. paid.2007.12.004. 
Nélis, D., Kotsou, I., Quoidbach, J., Hansenne, M., Weytens, F., Dupuis, P., \& Mikolajczak, M. (2011). Increasing emotional competencies leads to higher well-being, better subjective health, enhanced relationship quality, and increased employability. Emotion, 11, 354-366. doi: 10.1037/a0021554

Nelis, D., Quoidbach, J., Mikolajczak, M., Hansenne, M. (2009). Increasing emotional intelligence: (How) is it possible? Personality and Individual Differences, 47, 36-41. doi: 10.1016/j.paid.2009.01.046.

Petrides, K. V. (2009). Psychometric properties of the Trait Emotional Intelligence Questionnaire. In C. Stough, D. H. Saklofske, \& J. D. Parker, Advances in the assessment of emotional intelligence. (pp.21-33). New York: Springer. doi: 10.1007/978-0-387-88370-0_5.

Petrides, K. V., \& Furnham, A. (2000). On the dimensional structure of emotional intelligence. Personality and Individual Differences, 29 (2), 313-320. doi: 10.1016/S0191-8869(99)00195-6.

Petrides, K. V., \& Furnham, A. (2003). Trait emotional intelligence: Behavioural validation in two studies of emotion recognition and reactivity to mood induction. European Journal of Personality, 17, 39-57. doi: 10.1002/per.466.

Petrides, K. V., Frederickson, N., \& Furnham, A. (2004). The role of trait emotional intelligence in academic performance and deviant behaviour at school. Personality and Individual Differences, 36, 277-293. doi:10.1016/S0191-8869(03)00084-9.

Petrides, K. V., Pe'rez-Gonza'lez, J. C., \& Furnham, A. (2007). On the criterion and incremental validity of trait emotional intelligence. Cognition and Emotion, 21, 26-55. doi:10.1080/02699930601038912.

Petrides, K. V., Sangareau, Y., Furnham, A., \& Frederickson, N. (2006). Trait emotional intelligence and children's peer relations at school. Social Development, 15, 537-547. doi: 10.1111/j.1467-9507.2006.00355.x.

Ruttledge, R. A., Petrides, K. V. (2011) A cognitive behavioural group approach for adolescents with disruptive behavior in schools. School Psychology International, 33 (2), 223-23. doi: 10.1177/0143034311415908.

Smith, L., Heaven, P. C. L., \& Ciarrochi, J. (2008). Trait emotional intelligence, conflict communication patterns, and relationship satisfaction. Personality and Individual Differences, 44, 1314-1325. doi:10.1016/j. paid.2007.11.024.

Tiabashvili, T., Mirtskhulava, R. \& Japaridze, M. (2015). Increasing emotional intelligence among early adolescents: Mythodrama group psychotherapy approach. Problems of Education in the 21 ${ }^{\text {st }}$ Century, 66 (66) 67-74.

Turashvili, T., Japaridze, M. (2013). Coping Strategies of University Students in Georgian Context. Problems of Education in the $21^{\text {st }}$ Century, 56, 144-149.

Villanueva, J. J., \& Sanchez, J. C. (2007). Trait emotional intelligence and leadership self-efficacy: Their relationship with collective efficacy. Spanish Journal of Psychology, 10, 349-357. doi: 10.1017/ S1138741600006612.

Received: November 30, 2018

Accepted: December 24, 2018

Tinatin Tiabashvili $\quad \mathrm{PhD}$, Invited Teacher, llia State University, Cholokashvili, 3/5, Tbilisi, Georgia.

E-mail: Tinatin.tiabashvili@iliauni.edu.ge

Rusudan Mirtskhulava $\quad \mathrm{PhD}$, Associated Professor, llia State University, Cholokashvili, 3/5, Tbilisi, Georgia.

E-mail: Rusudan.mirtskhuava@iliauni.edu.ge

Marine Japaridze $\quad$ PhD, Full Professor, llia State University, Cholokashvili, 3/5, Tbilisi, Georgia.

E-mail: Marine_japaridze@iliauni.edu.ge 